\title{
Direct Synthesis of MCM-41 Mesoporous Aluminosilicates Containing Au Nanoparticles in Aqueous Solution
}

\author{
Hong-Ping Lin, ${ }^{* \dagger}$ Yu-Shan Chi, ${ }^{\dagger \dagger}$ Jiunn-Nan Lin, ${ }^{\dagger \dagger}$ Chung-Yuan Mou, ${ }^{\dagger \dagger}$ and Ben-Zu Wan ${ }^{\dagger \dagger \dagger}$ \\ Institute of Atomic and Molecular Sciences, Academia Sinica, P.O. Box 23-166, Taipei, Taiwan 106 \\ ${ }^{\dagger}$ Department of Chemistry and Center of Condensed Matter Science, National Taiwan University, Taipei, Taiwan 106 \\ ${ }^{\dagger \dagger}$ Department of Chemical Engineering, National Taiwan University, Taipei, Taiwan 106
}

(Revised June 27, 2001; CL-010611)

A mesoporous MCM-41 aluminosilicate containing $\mathrm{Au}$ nanoparticles catalyst of high surface area and porosity has been conveniently prepared in a simple embedding approach.

Mesoporous silica, possessing the advantages of high surface area $\left(\sim 1000 \mathrm{~m}^{2} / \mathrm{g}\right)$ and tunable pore size $(2.0-30 \mathrm{~nm})$, has been considered as useful catalytic supports. ${ }^{1,2}$ Among the catalysts, the noble metal Au nanoparticle is interesting for its catalytic activity in many important reactions. ${ }^{3,4}$ A nano-hybrid of Au nanoparticles and mesoporous silica could be an interesting catalyst system for versatile applications, especially for molecules too large to fit in the pore of traditional zeolites.

In the literatures, chemical vapor deposition (CVD) and precipitation methods by using various Au precursors are the two common approaches for preparing the Au/mesoporous silica catalyst system. ${ }^{5,6}$ Recently an efficient catalyst prepared from a CVD method had been reported, ${ }^{6}$ however, the organic Au precursors for CVD are expensive. In the precipitation procedure, the affinity of Au source may not be strong enough to deposit on silica. A simple and economic method is thus still desirable. In this paper, we report a convenient way directly to synthesize a nanocomposite of $\mathrm{Au} /$ mesoporous aluminosilicate material (denoted as Au/MCM-41 hereafter) with high surface area in aqueous solution. We then use the $\mathrm{CO}$ oxidation reaction to test its catalytic activity.

The basic idea for preparing the mesoporous MCM-41 aluminosilicates containing $\mathrm{Au}$ nanoparticles in aqueous solution is: (1) the hydrophobic Au nanoparticles can be formed and preserved in the micelles of quaternary ammonium surfactants, ${ }^{7}$ and (2) the Au/surfactant system is used directly in a typical synthesis of MCM-41 mesoporous materials where the same surfactant is employed as template. The synthesis process is as follows: an aqueous solution of a tetrachloroaurate salt $\left(\mathrm{AuCl}_{4}^{-}\right)$ was mixed with cetyltrimethylammonium bromide $\left(\mathrm{C}_{16}\right.$ TMAB) solution to give a yellow-colored solution. This solution was reduced by adding aqueous sodium borohydride $\left(\mathrm{NaBH}_{4}\right)$ dropwise at $40{ }^{\circ} \mathrm{C}$, and a red-brown Au-nanoparticles solution was formed. Then the desired amount of sodium silicate and sodium aluminates was added into the Au-surfactant solution. After a neutralization procedure (the final $\mathrm{pH}$ value of the gel solution is about $8-10$ ), a red precipitate-gel solution was formed. Overall, the molar ratio of the gel is $1.0 \mathrm{SiO}_{2}: 0.028 \mathrm{NaAlO}_{2}$ : $0.71 \mathrm{C}_{16}$ TMAB : (0-0.042) $\mathrm{HAuCl}_{4}:(0-0.285) \mathrm{NaBH}_{4}: 0.6$ $\mathrm{NaOH}: 0.24 \mathrm{H}_{2} \mathrm{SO}_{4}: 300 \mathrm{H}_{2} \mathrm{O}$. The gel solution was then transferred to an autoclave to undergo hydrothermal reaction at $100{ }^{\circ} \mathrm{C}$ for 2 days. Finally, filtration, washing, drying and calcination at $560{ }^{\circ} \mathrm{C}$ gave the $\mathrm{Au} / \mathrm{MCM}-41$ materials.

Figure 1A shows the reflectance UV-vis spectra of the cal-
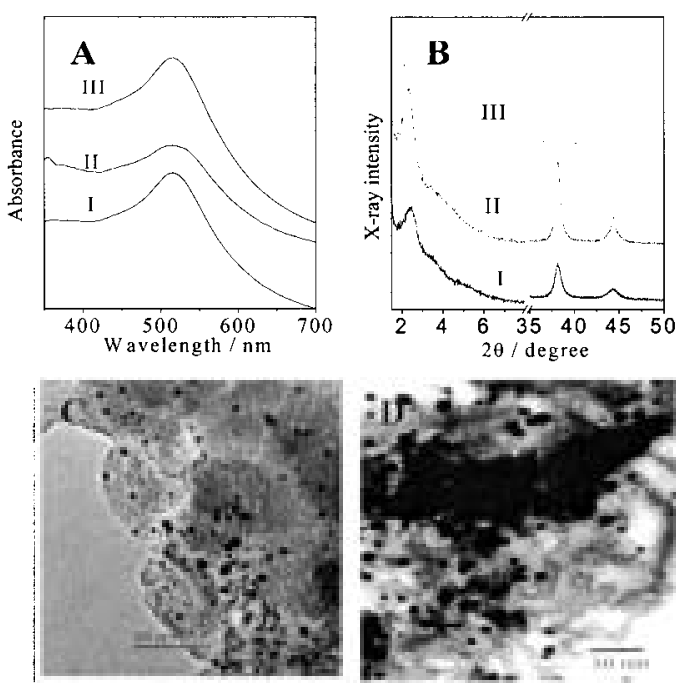

Figure 1. Reflectance UV-vis spectra (A): I, Au/ $/ \mathrm{SiO}_{2} \mathrm{wt} \%=4.0$ $\% ; \mathrm{II}, \mathrm{Au} / \mathrm{SiO}_{2} \mathrm{wt} \%=8.0 \%$; III, $\mathrm{Au} / \mathrm{SiO}_{2} \mathrm{wt} \%=12 \%$. XRD patterns (B). HR-TEM micrographs of sample I and II (C, D) of the $\mathrm{Au} / \mathrm{MCM}-41$ catalyst with different loading of $\mathrm{Au}$.

cined Au/MCM-41 materials at various Au loading. All the samples show the surface plasmon resonance absorption peaks at about $520 \mathrm{~nm}$, indicating the existence of the Au nanoparticles in these samples. In Figure 1B, the XRD peak at low angle corresponds to the mesostructures of MCM-41, and the two peaks at high angle are due to the Au nanoparticles. Compared with unloaded MCM-41 materials where at least three low angle peaks can be seen, the absence of (110) and (200) peaks in $\mathrm{Au} / \mathrm{MCM}-41$ indicates the pore structure is less ordered. Using Scherrer equation, the average size of the Au particles was estimated to be about $8-10 \mathrm{~nm}$. To further examine the form of deposited Au nanoparticles and the mesostructures of MCM-41 materials, TEM micrographs of the samples with various Au content were taken (Figures 1C and 1D). As shown in both TEM micrographs, the mesostructures of the MCM-41 aluminosilicates containing Au nanoparticles are less ordered as that of typical MCM-41 samples. Nonetheless, aligned linear array of channels can be observed. However, the order is disrupted around the embedded $\mathrm{Au}$ nanoparticles. With careful observation, one can find that the Au nanoparticles $(>5 \mathrm{~nm})$ are always larger than the mesopore size $(<3 \mathrm{~nm})$ of the MCM-41 aluminosilicates. Thus, most of Au nanoparticles are not confined within single nanochannel of the MCM-41 aluminosilicates. This explains that the structural order of Au/MCM-41 was relatively poor. One can also find some of the Au nanopar- 
ticles are attached to the outer surface of the micro-particles of MCM-41 aluminosilicates, but most are embedded in the particulate of MCM-41 aluminosilicates (Figures 1C and 1D). The sizes of the Au nanoparticles are measured, and they are distributed from 5 to $15 \mathrm{~nm}$ with mean value of about $8 \mathrm{~nm}$. This value is in agreement with the size calculated from Scherrer equation. Analyzing the TEM micrographs of samples with two different $\mathrm{Au}$ contents, we found that the percentage of Au nanoparticles larger than $10 \mathrm{~nm}$ increases with the increase of Au content.

Combined with the $\mathrm{N}_{2}$ adsorption-desorption isotherm data of all the samples aforementioned, the basic physical properties are listed in Table1. The Au/MCM-41 aluminosilicates have the advantages of high surface area $\left(>900 \mathrm{~m}^{2} / \mathrm{g}\right)$ and large pore volume $\left(>0.7 \mathrm{~cm}^{3} / \mathrm{g}\right)$ as well as MCM-41 materials. This also shows that incorporation of $\mathrm{Au}$ nanoparticles in MCM-41 does not have a drastic pore-blocking effect on its nanochannels. In addition, the Au/MCM-41 still preserves the thick structural wall (about $2.0 \mathrm{~nm}$ ) and uniform pore size characteristic of the delayed acidification synthesis of unloaded MCM-41. ${ }^{8}$ The Au/MCM-41 thus possesses the good thermal and hydrothermal stability, and high adsorption ability for reaction agents. ${ }^{1,2}$

Table 1. The physical properties of the MCM-41 mesoporous aluminosilicates containing $\mathrm{Au}$ nanoparticles with various $\mathrm{Au} / \mathrm{SiO}_{2} \mathrm{wt} \%$ ratios

\begin{tabular}{c|ccccc}
\hline $\begin{array}{l}\text { Loading } \\
\text { (Au wt\%) }\end{array}$ & $\begin{array}{c}\text { XRD d } \mathrm{d}_{100} \\
(\mathrm{~nm})\end{array}$ & $\begin{array}{c}\text { Pore size } \\
(\mathrm{nm})\end{array}$ & $\begin{array}{c}\text { Wall Width S.A.BET } \\
(\mathrm{nm})^{\mathrm{a}}\end{array}$ & $\begin{array}{c}\text { Porosity } \\
\left(\mathrm{m}^{2} / \mathrm{g}\right)\end{array}$ & $\begin{array}{c}\mathrm{b} \\
\left(\mathrm{cm}^{3} / \mathrm{g}\right)\end{array}$ \\
\hline 0.4 & 3.58 & 2.00 & 2.14 & 988 & 0.74 \\
4.0 & 3.77 & 2.22 & 2.13 & 956 & 0.72 \\
8.0 & 3.77 & 2.53 & 1.82 & 920 & 0.70 \\
0 & 3.90 & 2.50 & 2.00 & 1046 & 0.78 \\
\hline
\end{tabular}

${ }^{\mathrm{a}}$ Wall width $=2 \mathrm{~d}_{100} / \sqrt{3}$-pore size. ${ }^{\mathrm{b}} \mathrm{N}_{2}$ adsorption volume at $\mathrm{p} / \mathrm{p}_{0}$ $=0.9$.

This synthesis procedure can be easily extended to other alkyltrimethylammonium bromides $\left(\mathrm{C}_{\mathrm{n}} \mathrm{TAMB}\right.$, with $\left.\mathrm{n}=12-18\right)$ silica systems. By changing the chain length of surfactant templates, one could control the pore size of AuMCM-41 materials.

It is expected that the Au/MCM-41 nanocomposite porous materials regarded as a kind of highly dispersed Au nanoparticles within high surface area supports, would possess versatile catalytic capability. To investigate the catalysis activity of the $\mathrm{Au} / \mathrm{MCM}-41$ system, $\mathrm{CO}$ oxidation reaction was chosen as the test reaction. Figure 2 shows that the Au/MCM-41 with $\mathrm{Au}$ loading of 4 to $12 \mathrm{wt} \%$ has the capability to catalyze the CO oxidation reaction at $80{ }^{\circ} \mathrm{C}$. The relatively low reactivity (less than $16 \%$ conversion) in $\mathrm{CO}$ oxidation of our Au/MCM-41 catalysts is due to the large size of Au nanoparticles (> $5 \mathrm{~nm}$ ) we made. ${ }^{5}$ Further reduction of the size of Au nanoparticle would be desirable for optimizing the catalytic activity. Nevertheless, we have demonstrated a well-dispersed nanoparticles of gold in

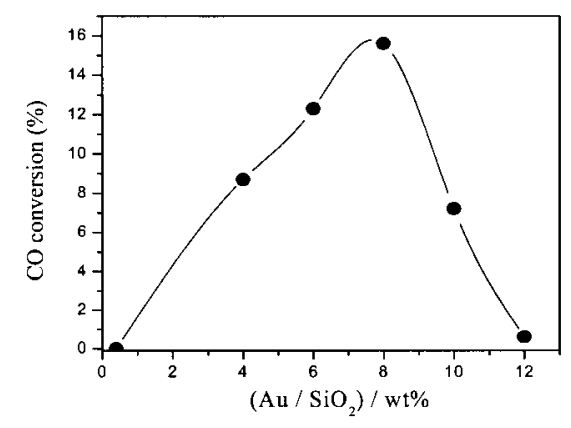

Figure 2. CO conversion over mesoporous MCM-41 aluminosilicate $(\mathrm{Si} / \mathrm{Al}=37)$ containing $\mathrm{Au}$ nanoparticles with different $\mathrm{Au}$ content (the reaction condition: in a $\mathrm{CO} /(\mathrm{CO}+$ air $)=$ $1 \%$ gas, $\mathrm{T}=80^{\circ} \mathrm{C}$, pressure $=1 \mathrm{~atm}$ and $\mathrm{WHSV}=9 \times 10^{4} \mathrm{~mL} / \mathrm{h}$ $\mathrm{g})$.

Au/MCM-41 catalytic system, which possesses the advantages of high surface area, large porosity and pore size, and thermal stability that may be useful in other catalytic reaction involving larger molecules. Further studies for this system is undergoing.

There exist many factors, such as surface area, porosity, dispersion of the catalytic centers, which would significantly influence the activity of the catalyst. ${ }^{5}$ Furthermore, the surface silanol groups on the wall of the MCM-41 aluminosilicates would allow us to functionalize them to help the adsorption of the selected reactants. Thus, the strategies for synthesizing the supported nanoparticles for catalysis need to be further developed.

This research was financially supported by the Chinese Petroleum Co. and the National Science Council of Taiwan (NSC 89-2113-M-002-028).

\section{References and Notes}

1 T. Yanagisawa, T. Shimizu, K. Kuroda, and C. Kato, Bull. Chem. Soc. Jpn., 63, 988 (1990).

2 C. T. Kresge, M. E. Leonowicz, W. J. Roth, J. C. Vartuli, and J. S. Beck, Nature, 359, 710 (1992).

3 M. Haruta, Catal. Today, 36, 153 (1997).

4 J. -D. Grunwaldt, C. Kiener, C. Wogerbauer, and A. Baiker, J. Catal., 181, 223 (1999).

5 A. I. Kozlov, A. P. Kozlov, H. Liu, and Y. Iwasawa, Applied Catalysis A, 182, 9 (1999).

6 M. Okumura, S. Tsubota, M. Iwamoto, and M. Haruta, Chem. Lett., 1998, 315.

7 T. Miyao, N. Toyoizium, S. Okuda, Y. Imai, K. Tajima, and S. Naito, Chem. Lett., 1999, 1125.

8 a) H. P. Lin and C. Y. Mou, Science, 273, 765 (1996). b) H. P. Lin, S. Cheng, and C. Y. Mou, Microporous Mater., 10, 111 (1997). 